\section{TERMINOLOGIE - DIE GESAMENTLIKE WAPEN}

Vooruitgang in alle menslike strewe op aarde hang ten nouste saam met die effektiewe oordrag of kommunikasie van inligting. Die kommunikasie is eers effektief as dit die saakmakende ontvanger so bereik dat hy of sy daarop kan reageer. Om dié rede moet die kommunikasiemedium of taal duidelik (ondubbelsinnig) wees. Ondubbelsinnige kommunikasie is egter slegs moontlik indien die begrippe - die elemente van die dinkproses dieselfde betekenis dra vir al die deelnemers in die kommunikasieproses. En dit is so vir sowel nasionale as internasionale informasie-uitwisseling.

\section{Wat is terminologie?}

Die ontwikkeling van die menslike taal strek vanaf die gevoelsklanke (wat na buitetalige dinge verwys) gebruik vir ekspressie en kommunikasie met ander tot die strukturering in redelik vormvaste simbole van klanke, woorde en frases wat ook na ontasbare dinge verwys. Nog later ontwikkel die skriftekens van die simbole in letters of idiograwe, wat op skrif woorde en frases uitbeeld, en op hoër sintakties-stilistiese vlak sinne vorm ter aanduiding van buitetalige sake of begrippe. Aanvanklik het die woorde na huishoudelike bedrywe soos saai, kossoek, jag, kook, veeboerdery, seevaart, ens. verwys. Op hierdie vlak kan 'n mens beswuarlik van terminologie praat, bloot van vakwoorde. Later ontstaan as gevolg van toenemende industrialisering en organisering in gildes of instellings spesifieke tegniese vaktale of tegnolekte. Dié indelings het in ' $n$ toenemende mate ' $n$ eiesoortige taalontwikeling begin toon: spesiale idioom, uitdrukkings, formuleringswyse en styl, eiesoortige woorde oor spesifieke voorwerpe of begrippe. Hierdie taal van institute het toenemend vir die buitestaanders onverstaanbaar geword. Die tegnolekte kan beskrywe word as terminologie: 'Geinstitusionaliseerde taalpatrone ter uitkenning van bepaalde tegnologiese of wetenskaplike begrippe.'

\section{Hoekom moet ons normeer?}

As gevolg van die ekskalerende wetenskap en tegnologie brei die gewone gemeenskaplike taalskat van ' $n$ taal soos Engels wat ongeveer 600000 woorde het, ten opsigte slegs van die elektriese ingenieurswese uit tot meer as 4 miljoen begrippe wat name moet kry. Met hierdie onhanteerbare woordeskat sou die vrye ontwikkeling van terminologie lei tot ' $n$ onhoudbare verwarring. Om hierdie rede het terminoloë reeds aan die begin van ons huidige eeu kommissies begin stig vir die eenvormigmaking van begrippe en terme sodat kom- munikasie ekonomies en dus effektief kan plaasvind. Ter illustrasie: vir die begrip of idee van die periodieke oliewisseling en nagaan van 'n motorvoertuig word in Afrikaans verskeie woorde (simbole gebruik: diens, diensing, oliewisseling, versiening wat uiteenlopende betekenisse voor die gees roep: diensverpligting, 'diensing': verkeerde woordbou, oliewisseling, versiening (nasien), sodat die boodskap verskillende ontvangers verskillend gaan laat reageer. As ons nou tussen alle gebruikers ooreen sou kom om die voorwerp (proses) van gereelde oliewisseling en nagaan van ' $n$ motorvoertuig die simbool 'versiening' te gee met as betekenis die beskrywing hierbo, het ons terminologies normerend te werk gegaan:

a. Ons het ooreenkoms gekry oor die juiste term volǵens 'n sekere kriterium (norm, standaard);

b. Ons het die norm beskryf deur middel van definisie;

c. Ons het deur middel van die term dus ' $n$ vaste betekenis aan 'n sekere taalsimbool (term) geheg wat

d. tans ondubbelsinnige kommunikasie moontlik sal maak.

Binne die militêre bestek kan ' $n$ leemte in taalkommunikasie vanuit die oogpunt van koste-effektiwiteit ander pogings waaraan baie tyd en fondse bestee is, verydel. Byvoorbeeld ' $n$ hofsaak van ongeveer R30 miljoen waar die Engelse 'control' wanvertaal is as 'kontrole' sodat die hoofkontrakteur geen 'beheer' uitgevoer het nie. Of wanneer iemand wat in ' $n$ ligte vliegtuig bo die Magaliesberge in ' $n$ digte mis vlieg en die beheertoring op Wonderboom sê sy 'hoogte' is $5000 \mathrm{vt}$, is dit in werklikheid nie hoogte bo die berg nie maar hoogte bo seespieël ('altitude'). Hy vlieg hom dood teen die berg want sy werklike hoogte bo die berg was -2 voet! ${ }^{2}$

Weber vergelyk taal met stoom; dit verdamp en kondenseer in nuwe skeppings. ${ }^{3}$ Binne bepaalde situasies is die mens egter gebonde tot ' $n$ beperkte kode van kommunikasie; dis wanneer hy in ' $n$ winkel as koper kom of 'n poskantoor, bioskoop of fabriek betree. Dan pas die besoeker sy kode van taalgebruik aan by die algemeen aanvaarbare in die situasie. Dit kan beskryf word as situasioneel gebonde taal want slegs binne die situasie behou woorde hul duidelik omlynde betekenis: (toneel)

1. J.H. Picard: Die Probleem van Normering, (Pretoria, 19771.

2. '. iid.

3. M. Weber: soos aangehaal in Kirsipuu, An Interpretative Model, (Pretoria, 1975) 
'verhoog', 'regisseur'; (motorherstelplek) 'suier', 'ruitveër'. Die woorde is minder vry as die gewone gebruikswoorde buite die situasie: dit kan met die toestand van water vergelyk word.

Die derde tipe kode wat die kommunikerende mens aanwend, is die suiwer gerbruikskode. Hier vervul die taal byna 'n sekondêre rol en is die toegewese begrippe primêr; die taaltekens kry eers hulle sin binne die kader van die hele begrippestelsel ten opsigte waarvan hulle gedefinieer word. Dit is die domein van die tegnologiese, wetenskaplike en geesteswetenskaplike vaktaal waar elke begrip sorgvuldig binne 'n bepaalde stelsel afgepen word en binne die stelsel ook sy definisie ontvang, en sy simbool of term waarvolgens dit voortaan gebruik sal word om na dié besondere begrip te verwys. Die term met sy definisie is duidelik ' $n$ verwysingsmiddel vir die wetenskaplike of tegnikus wat hy daagliks binne sy milieu moet gebruik om 1 . self duidelikheid te verkry oor sy eie begrippe; 2 . die begrippe aan sy kollegas te kommunikeer; 3. die begrippe aan ander publieke oor te dra.

Om dit te kan doen, moet wetenskaplikes, tegnici en vakmanne binne hulle onderskeie begrippevelde dieselfde betekenisse heg aan gesamentlike vakterme. Dit impliseer dus standaardisering of normering. Dit is in 'n groot mate ' $n$ 'verwysing' van die woord, 'n inperking tot 'n bepaalde simbool of kodeteken, geheg aan 'n definisie wat dan help om vakkommunikasie op behoorlike grondslag moontlik te maak.

Om die onderlinge terminologie te koördineer, terme te promulteer en die gebruik daarvan tussen die vakgroepe te bestendig, is 'n gesag nodig; die gesag van 'n nasionale (of selfs internasionale) termnormerende liggaam. ' 'n Term is dus 'n genormeerde simbool, teken, woord of uitdrukking deur natuurwetenskaplike of tegnologiese vakindelings onderling gebruik as vakkommunikasiemiddel. ${ }^{4}$ En terminologie is die dissipline wat hom besig hou met die ontstaan ot skepping van kriteria vir optekening, verspreidiny en bestendiging, promulgering, normering of verandering in die tegnolek.

Die hele terminologieproses staan in die teken van normering. Daar bestaan norme vir gebruiklikheid in die besondere vakgebied (dus tussen die spesialiste); daar is ook norme (kriteria) vir optekening, redaksionele prosedures, taalkundige en leksikografiese versorging, en daar is tewens norme vir die bestendiging en/of verandering van vakterme.

\section{Botsing tussen norm en gebruik}

Die individuele spraakaksie is die realisering van die taalsisteem in ooreenkoms met gebruik of die norm. Indien dit te ver van die sisteem afwyk, word die uiting onverstaanbaar. Daar is heelwat gevalle van 'n botsing tussen gebruik en norm: byvoorbeeld 'n waarskuwing soos 'moenie rook' sonder 'nie' of om 'her te waardeer' in plaas van om te 'herwaardeer'. Elke spraakaksie is 'n vernuwingsuiting van die sisteem en die norm is die fase waar outoriteit intree en daar geen vernuwing meer is nie. Die hoofrede vir normering is vergemakliking van tegniese en wetenskaplike kommunikasie. Tegniese terminologie is, uit die aard van sy funksie, 'n hoogs beperkte taal.

Die inherente weerstand teen tegniese taalnorme bestaan hierin dat die algemene taal se norme onder sosiale druk gehandhaaf word terwyl die vaktermnorm 'n doelbewuste afdwingpoging deur 'n spesiale groep inhou. Maar dit is amper onmoontlik om 'n vaktermnorm af te dwing wat teen die sterk geykte gebruik indruis. 'Beeldradio' is 'n nuwe Germaanse woord maar hy kan nie opweeg teen die internasionaal aanvaarde televisie nie, en dit wil voorkom of die woord 'versien' (vir service') nie die pas sal volhou teen 'diens', of 'instandhouding' ('maintenance') teen 'onderhoud' nie. Daar is tewens baie gevalle van onsekerheid oor norm of gebruik bv 'rand', (meervoud) 'rand' of 'rande'; 'Staandemaglid' of 'Staande Maglid'?

\section{Doeltreffendheid van terme}

Die volgende faktore bepaal die doeltreffendheid van vakterminologie: 5

1. Vlak of peil: norm, gebruik, sisteem.

2. Mode: oorredend, ekspressief, mededelend.

3. Afwykingstipe: register, semanties, sintakties, morfologies, ortografies.

4. Uitwerking: verstaanbaarheid, gerief, redundansie, logika.

Die Terminologie het terme om begrippe te benoem, te kategoriseer en oor te dra. 'n Bepaalde term is meestal ' $n$ arbitrêre teken of simbool vir die begrip en daarom is dit noodsaaklik om die plek van elke ondergeskikte begrip en aspek binne die globale begrippesisteem te definieer. Dit is ook die benadering wat Wüster volg. ${ }^{6}$ Vir hom is die definisie die prioriteit; eers ná die definisie die begrip binne die stelsel vasgepen het, kan die benoeming of 'beterming' van die begrip volg. En in

4. J.H. Picard: op cit.

5. I. Pinchuk: Freedom and Constraint in Technical Langyage, (Pretoria, 1974) 
hierdie benoemingsproses moet ' $n$ mens in gedagte hou dat daar wel, vanweë die internasionale aard van die wetenskap en tegnologie, bepaalde wetenskaplike universalia bestaan. Daar is, afgesien van kulturele verskille van register, sekere ooreenkomste tussen die begrippe van alle mense, wat ook al hulle tale mag wees, want vertaling sou hiersonder inderdaad onmoontlik wees.

\section{Woord- en termvorming}

Elke lewende taal klassifiseer sy woordeskat volgens 3 prinsipes:

\section{Woordvormingsreëls in sy grammatika: vrag + boot $=$ 'vragboot'}

2. Ontlening uit ander tale: 'handelskip': leenvertaling van 'merchant ship'

3. Beterming met onverbonde woorde uit 'n taal: 'koopvaarder' (ou vorm).

In die eerste geval sal die :voordvormingsreëls bepaal dat 'vliegdeklandingskip-en-opstygvliegtuig' onhanteerbaar en onaanvaarbaar is, terwyl 'deklandingsvliegtuig' wel bruikbaar is. Ons leer dus woorddele aan as afsonderlike boustukke saam met hulle verbindingsreëls. So kan ons nuwe samestellings of verbindings skep. Cluver sê: 'Dit volg dat 'n deel van die kriteria wat die verstaanbaarheid van 'n samestelling bepaal, die resultaat is van die aard en aantal reëls wat toegepas moet word om die samestelling tot 'n onderliggende sin te reduseer.' 7 Ek dink dat baie van ons aanmekaarskryfprobleme en lang onbruikbare terme uit hierdie soort benadering volg. Die sogenaamde woorddefinisies is onooglike lang komposita waarin soveel moontlik aspekte van die begrip opgeneem word: 'senderelementinsteltydreëlingsoutomaat', die resultaat van 'n hele reeks transformasies op 'n onderliggende sin toegepas. Kommunikasie word vanweë die te veel aan transformasies menslik onmoontlik.

Dit is baie duidelik dat termnormering op grond van duidelik begripsdefiniëring 'n kardinale faset van enige militêre stelsel moet vorm. Immers, die effektiewe oordrag van en reaksie op opdragte en instruksies, en dus duisende menselewens, hang hiervan af.

\section{Terminologie op strategiese beleidsvlak}

As mens daaraan dink dat die aanslag teen die Republiek van Suid-Afrika oor agt dimensies loop: militêr, politiek, ekonomies, sielkundig, ideologies, diplomaties, kultureel en ook semanties, is enige strategiese beplanning wat minder fasette as dit dek, ontoereikend. Die term strategie het so in die moderne tydsgewrig 'n gesamentlike veelsnydende swaard geword; gesamentlik, want tensy alle fasette van die staatsbestel saam in 'n konfliksituasie dieselfde betekenis aan 'n strategiese begripsterm heg, gaan dit lol. Strategie is eers omskryf as 'die kuns van oorlogvoering' veral, so sê Van Dale: 'Voorzover deze bestaat in het maken en uitvoeren van plannen voor bewegingen op grote schaal'. 8 Maar dit is vandag die tweede omskrywing van Taktiek. 'Die skikking en maneuvrering van eenhede in verhouding tot mekaar en/of tot die vyand'. ${ }^{9 a}$ 'n Moderne omskrywing van strategie lui vandag:

'Beleid of patroon van doelstellings met as vernaamste elemente:

a. As Abstrakte begrip: Die wisselwerking tussen wilspartye om die gewenste beslissing in 'n konfliksituasie af te dwing;

b. As Eienskap: Die kuns (of genie) van 'n leier in 'n konfliksituasie;

c. As Wetenskaplike Dissipline: Die studie en formulering van grondliggende beginsels, reëls, riglyne wat die gehalte, doelmatigheid en effektiwiteit van optrede in 'n konfliksituasie bepaal;

d. As Beplanningsinstrument: Die denkwyse waarvolgens besin word oor die beste aanwending van die beskikbare en beplande middele om 'n konfliksituasie in eie guns te besleg;

e. As Produk: Die plan van optrede waardeur alle beskikbare middele gekoördineerd aangewend word ter verwesenliking van 'n doel.' $9 \mathrm{~b}$

So kom uit die wydsheid van die nuwe strategiese bestel waarvan so 'n definisie getuig, belangrike begrippe na vore wat ook definiëring soek: Beleid: as riglyn/e waarvolgens of waarbinne planne opgestel moet word om die bepaalde doel te bereik, Doel: die rigting waarin 'n organisasie beweeg om 'n besondere doelwit te bereik; Doelwit: 'n mylpaal na 'n doel; en Doelstelling: die omskrywing van 'n doel/doelwit. Maar die definisie van strategie roep verdere begrippe op: Totale oorlog, waarin dit gaan om die bedreiging van voortbestaan en waarin alle hulpbronne en wapens aangewend word, verg 'n Totale Strategie: 'Die metode of wyse waardeur 'n regering in 'n gegewe konfliksituasie alle middele waaroor hy beskik volgens 'n geïntegreerde patroon aanwend om die

4. E. Wüster: Die Vier Dimensionen, IGermersheim 1967)

7. A.D. de V. Cluber: Die Aard en Ontwikkeling van Afrikaans as Vaktaal, (Pretoria, 1975).

8. Van Dale, Groot Woordenboek der N. Taal, (Den Haag, 1969).

9a. Weermagswoordeboek, Rekenaaruitdruk, 1976 9b. Ibid. 
konflik in sy guns te besleg en so die doelstellings van sy beleid te verwesenlik.' ${ }^{\text {9c }}$

Maar binne die kader van hoëvlak-beplanning is daar verdere begrippe wat om beterming roep. Vroeër is daar geredekawel oor verantwoordelikheid en die feit dat dit nie gedelegeer kan word nie. Binne die bestel van gedesentraliseerde bestuur: (wat beskryf word as die toedeling van die verantwoordelikheid vir die meganika van bestuur (ondersoek, beraming, organisering) aan funksionele deskundiges, en die dinamika van bestuur (bevelvoering, koördinering en kontrole) aan lynbestuur, ${ }^{10}$ kan verantwoordelikheid, gekoppel aan die nodige bevoegdheid, wèl gedelegeer word; aanspreeklikheid ('accountability') vir die welslae of mislukking van die poging egter nie. 'n Verdere aspek (onder 'dinamika') verg aandag: kontrole. Kontrole (kontrolering) slaan op nagaan ('checking') terwyl 'control' (beheer) slaan op die leidingsaspek van bestuur. Maar die term bestuur self is nog nie duidelik van administrasie onderskei nie.

Cloete ${ }^{11}$ en ander beskou die globale oorhoofse funksie (in die Suid-Afrikaanse Weermag bestuur geag) as administrasie - vergelyk administrateur van 'n provinsie - terwyl hy bestuur as ' $n$ ander subkomponent beskou.

Miskien kan in so 'n semantiese dialektiek met vrug gebruik gemaak word van die linguistiese woordveld-tegniek. Toe Jost Trier in die jare dertig sy woordveldteorie geponeer het, het hy eintlik meer 'n histories-talige (diachroniese) as 'n vandagtalige (sinchroniese) doel nagestreef. Maar die leksikon toon vandag so 'n gestruktureerdheid en sistematiek dat semantiese verskille met vrug deur middel van die woordveld ondersoek kan word. ${ }^{12}$ Ter illustrasie dié woorde: 1. kontrole, 2. beheer, 3. bestuur, 4. administrasie (-simplisties) gemerk volgens die kriteria van leiding, inspeksie, werking, klerklike werk:-

Hieruit blyk dat beheer een, bestuur twee en administrasie ook twee aspekte met kontrole gemeen het maar dat die inspeksiefunksie slegs onder kon- trole val. Dit blyk ook dat die element van leiding binne militêre konnotasie by die term administrasie ontbreek. Nou kan (weer eens simplisties) gekonstateer word dat kontrole slaan op die inspeksie- en nie op die beheervlak nie en administrasie op die werking en klerkvlak en nie op die leidingsvlak nie. Die velde lyk so:

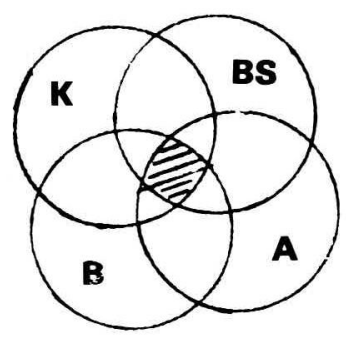

\section{Die benamings Terroris, Insurgent- en Guerrilla}

Indertyd met die polemiek oor die vervanging van die benaming 'terroris' deur 'guerrilla' het die politiek tot die terminologie toegetree. ${ }^{13}$ As 'n mens egter funksioneel kyk na wat die onderskeie 'termbekleërs' doen, is subjektiewe politieke semantiek nie bestand teen koue semantiese logika nie. 'n Guerrilla is 'n lid van 'n bende wat vyandelike aktiwiteite buite die raamwerk van 'n konvensionele militêre mag teen ' $n$ vyand voer (dit moet nie verwar word met paramilitêre magte nie). 'n Terroris is ' $n$ ondersteuner van 'n dissidente faksie wat gebruik maak van georganiseerde ge-

9c. Ibid.

10. W.J. de Villiers: Die Beginsels van Gedesentraliseerde Bestuur, (Johannesburg, 1973).

11. Telefoniese navrae aan universiteite (UNISA, UP) $1976-1977$.

12. J.Z. Uys: Van Woordveld via Komponentanalise tot sinvolle leksikonlemma, (Bloemfontein, 1977).

13. SAPA: Transvaler, 29 Oktober 1973.

\begin{tabular}{|l|c|c|c|c|}
\hline Kriterium & 1. Kontrole & 2. Beheer & 3. Bestuur & 4. Administrasie \\
\hline a. Leiding & $\checkmark$ & $\checkmark$ & $\checkmark$ & \\
\cline { 2 - 5 } $\begin{array}{l}\text { b. Inspeksie } \\
\text { c. Werking }\end{array}$ & $\checkmark$ & & & \\
\cline { 2 - 5 } d. Klerkwerk & & $\checkmark$ & $\checkmark$ & $\checkmark$ \\
\hline
\end{tabular}


weld om mense te dwing en te intimideer met die oog op politieke doelstellings. ' $n$ Insurgent is ' $n$ inheemse of vreemde onderdaan, nie deur internasionale reg as ' $n$ oorlogvoerende erken nie, wat probeer om ' $n$ wettige regering met geweld omver te werp.

Dit is duidelik sowel uit die uitsprake van bekende guerrillavegters en -deskundiges ${ }^{14}$ as uit die internasionaal-regtelike beskouing ${ }^{15}$ dat dié soort terrorisme waardeur burgerlikes in Suidelike Afrika bedreig word, nie as guerrilla-oorlog erken kan word nie look met die oog op die onwettigheid van hulle deurdringing en wreedaardige aanvalle op onskuldige burgers) en dat die deelnemers aan dergelike optrede dus ook nie die voorregte van die internasionale oorlogsreg kan geniet nie. Die term 'guerrilla' vir hierdie soort insurgensie was dus ongewens en het al tot groot misverstand gelei.

\section{SLOTSOM}

Dit is duidelik dat vaktermnormering, veral binne die militêre bestel, nie moontlik is sonder begripsnormering, saakstandaardisering en genormeerde definisie nie. Die soort benadering wat vir die SuidAfrikaanse Weermag die grootste voordeel inhou, is waar die vakspesialiste saam met die taalkundiges die onderliggende begrippe bestudeer, definieer en ooreenkom oor die korrekte terminologie. Dit is in wese hoe die huidige gesamentlike operasionele woordeboek opgestel word. Maar hiervoor is die medewerking van alle vakindelings en dissiplines binne die Weermag nodig. En dit moet so wees want 'n deskundige wat nie die terme op sy en verwante gebiede effektief kan hanteer nie, is geen deskundige nie.

Brig J.H. Picard.

14. Ché Guevara: On Guerrilla Warfare, (New York, 1962) 1962).

15. L. Oppenheim: International Law, (London, 1952).

16. Vaktaalburo van SA Akademie van Wetenskap en Kuns, Pretoria, 1970 